\title{
Original \\ Gastrointestinal Stromal Tumor - Experience From A Tertiary Care Center
}

Apticle

\author{
Kalidas Biswas ${ }^{1}$, Jayanta Kumar Das ${ }^{2}$, Swarnabindu \\ Banerjee $^{3}$, Shibashish Bhattacharyya ${ }^{3}$, Bishan Basu ${ }^{4}$, \\ Shibajyoti Ghosh ${ }^{5}$
}

\author{
${ }^{\prime}$ Department of Medical Gastroenterology, \\ ${ }^{2}$ Department of Anaesthesiology, \\ ${ }^{3}$ Department of Medical Oncology, \\ ${ }^{4}$ Department of Radiotherapy, \\ ${ }^{5}$ Department of Surgery, \\ Calcutta National Medical College \\ \& Hospital, Kolkata \\ Corresponding Author: \\ Dr Swarnabindu Banerjee \\ Email:dr.swarnabindubanerjee@gmail.com
}

\section{ABSTRACT}

Gastrointestinal stromal tumor( GIST ) is an uncommon entity in clinical practice. Though It is the commonest mesenchymal smooth muscle tumor, it accounts for only $<1 \%$ of all GI malignancies. Any part of gastrointestinal tract (GIT) may be involved. Stomach is the commonest site for this tumor. Other sites of GIT are also affected in this disease. Increasing awareness, newer diagnostic modalities and novel chemotherapeutic agents make the disease diagnosed earlier and successfully treated. Imatinib mesylate has changed the outcome of the disease .In Eastern part of India we have seen some cases over the years and expressed our observation here. Most of the patients were operated and later required Imatinib.

KEYWORDS: GIST, symptoms, surgery, imatinib.

\section{Introduction}

Gastrointestinal Stromal Tumours (GISTs) are the most common soft tissue sarcomas of the GI tract. GISTs can arise from anywhere of the GI tract, but stomach, where $60 \%$ of tumours are originated, is the common primary site followed by the small intestine, the region of origin for another $30 \%$ of cases. ${ }^{1}$ Esophagus, colon and rectum are other uncommon sites. Symptoms range from the vague ones like early satiety, abdominal fullness to pain abdomen and abdominal swelling. Gastrointestinal or intraperitoneal haemorrhage or more grave ones like acute abdomen like condition due to tumour rupture or acute obstruction due to tumour mass may lead to an acute medical emergency. ${ }^{2}$ Metastasis to liver or dissemination within the peritoneal cavity are the usual modes of distal spread. Suspected tumour type as well as the extent of spread guides the decision to take a biopsy. If preoperative therapy is considered, obtaining a tissue sample to confirm the diagnosis before any such intervention, is mandatory. ${ }^{2}$ For obtaining such sample, endoscopic ultrasound based fine needle aspiration (FNA) is preferred over percutanous biopsy, as the later is associated with more risks of intraperitoneal haemorrhage or tumour dissemination. Percutaneous route, though, may be more convenient route to rule out metastatic disease. ${ }^{3}$ Outcome of therapy or prognosis is related to the primary site of origin of the tumour, the size of it and the mitotic rate and the pathologic report must mention these factors. To make a proper assessment of the mitotic rate, the most 
proliferative region of the tumour should be evaluated and the reporting should be done as the number of mitoses per 50 high power fields. ${ }^{4-5}$

\section{Methods}

A retrospective analysis was performed with respect to disease presentation, disease course and long term outcomes.

\section{Results}

In our institution we have seen 13 patients of GIST from 2010 to 2017 (Table 1). Age ranging from 28 to 74 years with an almost equal incidence of sexes. Pain abdomen was the predominant symptom (8/13 patient). Two patients presented with GI bleed. One patient presented with abdominal mass. Three patients had features of bowel obstruction. Stomach (6/13) was the predominant site for disease. Small intestine was seem to be affected in three patients. Two patients had retroperitoneal involvement. One patient had site of involvement at mesentery while another one had multiple sites of involvement (periampullary region and cecum). All patients were essentially diagnosed histopathologically. CD117 was done in almost all patients. All but 1 patient underwent surgery. Most of the patients had definitive procedure and depending on the risk status chemotherapy with imatinib was initiated. Two patient was lost to follow up; while all other patients were on regular follow up. During the course of follow up, recurrence with deterioration noted in two patients. They were put on regular monitoring along with $\mathrm{CT}$ scan of abdomen along with escalated dosage and duration of imatinib. Two patients were lost

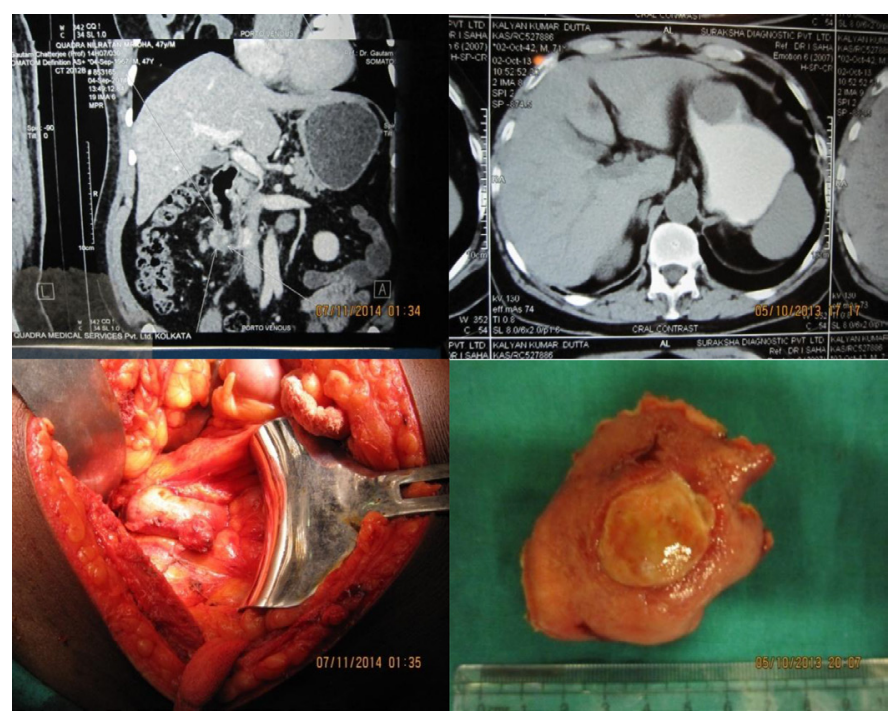

Figure 1: Photograph of duodenal GIST

Table 1: Demography of patient population.

\begin{tabular}{l|l|l|l|l|l|l|l|l} 
SI no & Age & Sex & Site & Presentation & Surgery & Chemotherapy & Recurrence & Date \\
\hline 1 & 55 & F & Stomach & Pain abdomen & Yes & Yes & Suspected & 2010 \\
\hline 2 & 60 & F & Stomach & $\begin{array}{l}\text { Pain abd. } \\
\text { Early satiety }\end{array}$ & Yes & Yes & Nil & 2011 \\
\hline 3 & 47 & M & Duod 2-3 & Vomiting & Yes & Yes & Nil & 2014 \\
\hline 4 & 50 & M & Retroperitoneum & Pain abd & Nil & yes & Nil & 2015 \\
\hline 5 & 60 & M & Stomach & UGI Bleed & Yes & nil & Lost to follow up & 2015 \\
\hline 6 & 52 & M & Jejunum & $\begin{array}{l}\text { Vomiting, } \\
\text { Pain abd. }\end{array}$ & Yes & Yes & Nil & 2016 \\
\hline 7 & 38 & F & Ileum & $\begin{array}{l}\text { Vomiting } \\
\text { Pain abd. }\end{array}$ & Yes & Nil & & \\
\hline 8 & 47 & M & Periampullary and colon & Pain abd. & Yes & Yes & Yes & 2016 \\
\hline 9 & 60 & F & Stomach & Pain abd. & Yes & Nil & Lost to follow up & 2016 \\
\hline 10 & 28 & F & Stomach & Pain abd. & Yes & Yes & Nil & 2016 \\
\hline 11 & 68 & M & Mesentery & Pain abd. & Nil & Yes & Nil & 2017 \\
\hline 12 & 74 & F & Stomach & UGI bleed & Yes & Yes & Nil & 2017 \\
\hline 13 & 50 & M & Retroperitoneum & Pain abd & Yes & Yes & Nil & 2017 \\
\hline
\end{tabular}


to follow up and rest 11 patients were regularly being monitored. Two patients had experienced recurrence of the disease and 9 patients were doing well till date. Periodic endoscopies, CT scan and relevant examinations were done in all patients.

\section{Discussion}

GIST is the commonest mesenchymal tumor. Stomach is known to be affected in $60 \%$ of cases. Small intestine is the site for 20 to $30 \%$ patients, rest are seen at esophagus, colon and rectum. Rectal GIST is the most aggressive one. Retroperitoneum is an uncommon site for this tumor. In our series stomach is the site of involvement for around $46 \%$ patients, Small intestine $25 \%$, and retroperitoneum was involved in $15 \%$ of patients. Mesentery and multiple site involvement ( $8 \%$ each) is the least common variety.

Tumour size and mitotic index of more than 5 mitoses/50 High Power Field are the chief prognostic factors for a given subsite, while the subsite of origin is a separate factor affecting outcome. Gastric GISTs are relatively indolent, while rectal GISTs are very aggressive. ${ }^{1}$ The presence of KIT and PDGFRA mutation is predictive of response to TKI therapy, while presence of SDH mutation signifies resistance to such therapies.

Imaging is useful for diagnosis, staging, restaging or for response evaluation and contrast-enhanced CT Scan is the usual choice for abdominal GISTs. MRI might be of additional help in some special circumstances like delineation of anatomic details of hepatic metastasis before surgical resection. PET/CT Scan is helpful to differentiate benign from malignant or necrotic mass from malignant tissue. In our series none of the patient undergone PET CT and all of them availed the facility of CT scan only.

However, if PET/CT Scan is planned to be used for follow up, a baseline PET/CT Scan is mandatory. ${ }^{2}$ PET can give an early assessment of response to Imatinib therapy if such evaluations are needed.

RECIST, WHO or Choi criteria are used to monitor response to therapy, all using CT Scan as primary modality of imaging. ${ }^{13-19}$ While some experts did opine that Choi criteria is the better way to evaluate response to Imatinib therapy, some others think RECIST or WHO criteria are better methods to response evaluation who are put on Sunitinib or Regorafenib after showing resistance to Imatinib therapy. ${ }^{13-17}$ EORTC has developed a separate metabolic response criteria for based upon PET/CT Scan findings. ${ }^{18}$

Surgery is the treatment of choice in tumours which are non-metastatic and resectable. In some nonmetastatic tumours, to make surgical resection easier, pre-operative Imatinib may be administered. The goal of surgery is complete resection with an intact pseudocapsule and negative microscopic margin. There is no evidence to support re-resection for microscopically positive margin. Lymph node dissections are, usually, not indicated. However, grossly enlarged nodes should be removed. ${ }^{20-21}$ Laparoscopic surgery is a good and acceptable alternative to the conventional laparotic approach. ${ }^{2,22-24}$ A metaanalysis from 19 studies pooling data of 1060 GIST patients show that there is no difference of outcome between laparoscopic and laparotomic approach, but laparoscopic approach was associated with shorter hospital stays, less blood loss and lower complication rates. ${ }^{25}$ In our patients laparoscopic approach was chosen as surgical methods. Two patients were not operated due to bad surgical risks and were directly put into imatinib therapy.

Targeted therapy aiming at KIT inhibition has emerged as the primary modality of therapy, along with surgery, in KIT positive GISTs. ${ }^{26}$ Long term followup data from B-2222 study confirmed that Imatinib mesylate produces durable disease response in patients with advanced GIST. ${ }^{27}$ Data from EORTC 62005 study and S0033/CALGB 150105 study have established that $400 \mathrm{mg}$ /day is an acceptable starting dose for Imatinib. For patients who had progressive disease following the above-mentioned dose of Imatinib, dose escalation to $800 \mathrm{mg} /$ day is an acceptable option (EORTC 62005 study). ${ }^{28-31}$ Most of our patients were on $400 \mathrm{mg}$ imatinib therapy.

RTOG0132/ACCRIN6665 was the first prospective study to establish the efficacy of imatinib in preoperative setting. ${ }^{33}$ Since then, numerous studies have been conducted, all showing dependable results. Maximal response may require more than six months of therapy and preoperative imatinib should only be used when there is 
a definite possibility of surgical risk reduction with usage of such therapy. ${ }^{34-37}$ None of our patients had received preoperative imatinib therapy.

Based on the encouraging results shown in ACOSOG Z9001 as well as in SSGXVIII/AIO, postoperative imatinib is recommended for all patients who are higher risk (high or intermediate risk groups) of recurrence. Risk of recurrence is determined by the primary tumour size, the mitotic index, non-gastric location and tumour rupture. Recommended duration of therapy is 36 months. Risk assessment for patients who did receive preoperative imatinib is difficult. So, they should receive adjuvant imatinib for at least 2 years. All of our patients received imatinib therapy and depending on the risk status, they had prolonged imatinib therapy in some patients. Patients who had residual disease after surgery should undergo repeat surgery and should receive imatinib irrespective of of second surgical status. The decision of surgery in patients with resectable, but metastatic disease is a controversial one, while patients with unresectable disease should receive preoperative imatinib. Evaluation for resectability is done by contrast-enhanced CT scan or MRI every 8-12 weeks. Patients with metastatic GIST should receive imatinib till progression of disease. ${ }^{38-42}$ None of our patients was operated for second time.

Progression of disease is defined as increase in tumour size and/or appearance of new lesions in CT scan or MRI, while PET/CT scans can help to clarify ambiguous lesions. Patients progressing on standard dose imatinib (400mg/day) can be shifted to higher dose protocol or switching to sunitinib. Patients progressing on high dose imatinib or sunitinib can be treated with regorafenib. In our series because of certain reasons and financial constraints we opted for imatinib therapy.

\section{Indian Data}

Indian data on GIST is limited. From this part of India we have no available data on GIST as noted with Pubmed search. Gupta et al presented their experience from SRMS-IMS of treating four cases of GIST of diverse stages. ${ }^{43}$ While in our study we encountered recurrence, Gupta et al had experienced recurrence free disease in their study. Suresh Babu et al presented their experience of treating 44 patients with metastatic GIST with imatinib. They reported a median PFS of 26 months, while their estimated median survival was 48 months. ${ }^{44}$ In our study we had metastatic disease in 2/13 patients and they were on imatinib therapy. Zanwar et al shared their experience of treating 23 cases of rectal GIST and concluded that neoadjuvant imatinib helps to spare the sphincter without any adverse effects on the overall outcome. ${ }^{45}$ Pai et al in their retrospective evaluation of 13 patients with rectal GISTs, out of which 11 were non-metastatic, revealed that sphincter preservation may not be feasible in spite of treatment with imatinib. ${ }^{46}$ However, we did not encountered any rectal GIST. Sahu et al reported their experience of treating 15 patients of GIST, who had developed imatinib resistance, with sunitinib. ${ }^{47}$ Yacob et al reviewed their experience of treating 150 patients of GIST at their centre ${ }^{48}$, while Borgaonkar et al shared their experience of successfully treating 15 such patients. ${ }^{49}$ We experienced a good response to surgery followed by imatinib therapy in most of our patients.

\section{Conclusion}

GIST in an uncommon tumor with protean manifestations. Our study with a small number of patients enlightened us with its variations. Surgery and chemotherapy with imatinib are acceptable modalities of treatment. In our experience overall prognosis is satisfactory unless metastasized. Multimodality and multispeciality treatment approach are essential to treat the disease.

\section{References}

1. Miettinen M, Lasota J. Gastrointestinal Stromal Tumors : pathology and prognosis of different sites; Semin Daogn Pathol 2006; 23; 70-83

2. Demetri GD, von Meheren M, Antonescu CR et al. NCCN Task Force Report; update on the management of patients with gastrointestinal stromal tumours; J Natl Compr Canc Netw; 2010;8; Suppl 2; S1-41

3. Sepy PS, Moparty B, Pitman MB et al; EUS-guided FNA for diagnosis of GI stromal tumors : sensitivity and cytologic yield; Gastrointest Endosc 2009; 70; 254-261

4. Fletcher CD, Berman JJ, Corless $\mathrm{C}$ et al. Diagnosos of gastrointestinal stromal tumors: a consensus approach; 
Hum Pathol; 2002; 33; 459-465

5. Heinrich MC, Corless CL, Duensing A et al. PDGFRA activating mutations in gastrointestinal stromal tumours; Science 2003; 299; 708-710

6. Hirota $\mathrm{S}$, Ohati A, Nishida $\mathrm{T}$ et al. Gain-of-function mutations of platelet-derived growth factor recptor alpha gene in gastrointestinal stromal tumour; Gastroenterology 2003; 125; 660-667

7. Miettinen M, Lasota J. Gastrointestinal Stromal Tumors : review of morphology, molecular pathology, prognosis and differential diagnosis; Arch Pathol Lab Med; 2006; 130; 1466-1478

8. Lasota J, Miettinen M. Clinical significance of oncogenic KIT and PDGFRA mutations in gastrointestinal stromal tumors; Histopathology 2008; 53; 245-266

9. Dow N, Giblen G, Sobin LH, et al. Gastrointestinal stromal tumors: differential diagnosis. Semin Diagn Pathol 2006;23:111-119.

10. Chirieac LR, Trent JC, Steinert DM, et al. Correlation of immunophenotype with progression-free survival in patients with gastrointestinal stromal tumors treated with imatinib mesylate. Cancer 2006;107:2237-2244.

11. Debiec-Rychter M, Wasag B, Stul M, et al. Gastrointestinal stromal tumours (GISTs) negative for KIT (CD117 antigen) immunoreactivity. J Pathol 2004;202:430-438.

12. Medeiros F, Corless CL, Duensing A, et al. KIT-negative gastrointestinal stromal tumors: proof of concept and therapeutic implications. Am J Surg Pathol 2004;28:889894.

13. Choi H, Chamasangavej C, Faria SC et al. Correlation of computed tomography and positron emission tomography in patients with metastatic gastrointestinal stromal tumor treated at a single institution with Imatinib Mesylate : proposal of new computed tomography response criteria; J Clin Oncol; 2007; 25; 1753-1759

14. Dudeck O, Zeile M, Reichardt P, Pink D. Comparison of RECIST and Choi criteria for computed tomographic response evaluation in patients with advanced gastrointestinal stromal tumor treated with Sunitinib; Ann Oncol; 2011; 22; 1828-1833

15. Schramm M, Englhert E, Schlemmer $M$ et al. Tumor response and clinical outcome in patients with metastatic gastrointestinal stromal tumors under Sunitinib therapy : comparison of RECIST, Choi and volumetric criteria; Eur J Radiol; 2013; 82; 951-958

16. Shinagare AB, Barysauskas CM, Braschi-Amirfarzan $M$ et al. Comparison of performance of various tumor response criteria in assessment of Sunitinb activity in advanced gastrointestinal stromal tumors; 2014; Eur J Oncol; 50; 981-986
17. Benjamin RS, Choi H, Macapinlac HA et al. We should desist using RECIST, at least in GIST; J Clin Oncol; 2007, $25 ; 1760-1764$

18. Young H, Braum C, Cremarius U et al. Measurement of clinical and subclinical tumor response using [18F]Fluorodeoxyglucose and positron emission tomography, review and 1999 EORTC recommendations; European Centre for Research and Treatment of Cancer (EORTC) PET Study group; Eur J Cancer; 1999; 35; 1773-1782

19. Pror JO, Montemurro M, Ocurto MV et al. Early prediction of response to Sunitinib after Imatinib failure by $18 \mathrm{~F}$-fluorodeoxyglucose positron emission tomography in patients with gastrointestinal stromal tumor; J Clin Oncol; 2009; 27; 439-445

20. Fong Y, Coit DG, Woodruff JM, et al. Lymph node metastasis from soft tissue sarcoma in adults. Analysis of data from a prospective database of 1772 sarcoma patients. Ann Surg 1993;217:72-77.

21. Davila RE, Faigel DO. GI stromal tumors. Gastrointest Endosc 2003;58:80-88.

22. Otani Y, Kitajima M. Laparoscopic surgery: too soon to decide. Gastric Cancer 2005;8:135-136.

23. Novitsky YW, Kercher KW, Sing RF, et al. Longterm outcomes of laparoscopic resection of gastric gastrointestinal stromal tumors. Ann Surg 2006;243:738745; discussion 745-747

24. Otani Y, Furukawa T, Yoshida M, et al. Operative indications for relatively small $(2-5 \mathrm{~cm})$ gastrointestinal stromal tumor of the stomach based on analysis of 60 operated cases. Surgery 2006;139:484-492.

25. Chen K, Zhou YC, Mou YP et al. Systematic review and meta-analysis of safety and efficacy of laparoscopic resction of gastrointestinal stromal tumours of stomach; Surg Endosc; 2015; 29; 355-367

26. Demetri G, von Mehren M, Blanke C, et al. Efficacy and safety of imatinib mesylate in advanced gastrointestinal stromal tumors. N Engl J Med 2002;347:472-480.

27. Von Meheren M, Heinrich MC, Joensu H et al. Followup results of 9 years of ongoing phase II B2222 trial of Imatinib mesylate in patients with unresctable or metastatic KIT+ gastrointestinal stromal tumours [abstract]; J Clin Oncol; 2011; 29 (15_supplement); Abstract 10016

28. Verweig J, Casali PG, Zalcberg J et al. Progression free survival in gastrointestinal stromal tumours with high-dose Imatininib : Randomized trial; Lancet; 2004; 364; 1127 1134

29. Zalcberg J, Verweig J, Casali PG et al. Outcome of patients with advanced gastro-intestinal stromal tumours crossing over to a daily imatinib dose of $800 \mathrm{mg}$ after progression 
on 400 mg; Eur J Cancer; 2005; 41; 1751-1757

30. Blanke CD, Demetri GD, von Meheren $\mathrm{M}$ et al. Long term results from a randomized phase II trial of standard dose versus higher dose imatinib mesylate for patients with unresectable or metastatic gastrointestinal stromal tumours expressing KIT; J Clin Oncol; 2008; 26; 620-625

31. Blanke CD, Rankin C, Demetri GD et al. Phase III randomized intergroup trial assessing imatinib mesylate at two dose levels in patients with unresectable or metastatic gastrointestinal stromal tumours expressing the kit-resctor tyrosine kinase: S0033; J Clin Oncol 2008; 26; 626-632

32. Casali PG, Zalcburg J, Le Cesne et al. Ten Years Progression Free and Overall Survival in Patients with Unresectable or Metastatic GI Stromal Tumours : Long term analysis of the European Organization of Reseach and Treatment of Cancer, Italian Sarcoma Group and Australasian Gastrointestinal Trial Group Intergroup Phase III Randomized Trial at two dose level; J Clin Oncol; 2017; 35; 1713-1720

33. Eisenberg BL, Harris J, Blanke CD et al. Phase II trial of neoadjuvant/adjuvant imatinib mesylate for advanced primary or metastatic/recurrent operable gastrointestinal stromal tumour: early results of RTOG0132/ACCRIN6665; J Surg Oncol; 2009; 92; 42-47

34. McAuliffe JC, Hunt KK, Lazar AJF et al. A randomized, phase II study of preoperative plus postoperative imatinib in GIST; evidence of rapid radiographic response and temporal induction of tumour cell apoptosis; Ann Surg Oncol; 2019; 16; 910-919

35. Fiore M, Palassini E, Furnagalli E et al. Preoperative imatinib mesylate for unresectable or primary unresectable gastrointestinal stromal tumour; Eur J Surg Oncol 2009; 35; 739-745

36. Blesius A, Cassier PA, Bertucci F, et al. Neoadjuvant imatinib in patients with locally advanced non metastatic GIST in the prospective BFR14 trial; BMC Cancer; 2011; $11 ; 72$

37. Eisenberg BL1, Judson I. Surgery and imatinib in the management of GIST: emerging approaches to adjuvant and neoadjuvant therapy; Ann Surg Oncol. 2004 May;11(5):465-75.

38. Corless CL, Ballman KV, Antonescu CR et al. Pathologic and molecular features correlate with long-term outcome after adjuvant therapy of resected primary GI stromal tumor: the ACOSOG Z9001 trial; J Clin Oncol. 2014 May 20;32(15):1563-70.

39. Dematteo RP, Ballman KV, Antonescu CR et al. Adjuvant imatinib mesylate after resection of localised, primary gastrointestinal stromal tumour: a randomised, doubleblind, placebo-controlled trial; Lancet. 2009 Mar 28;373(9669):1097-104.

40. Joensuu H, Eriksson M, Sundby Hall K et al. One vs three years of adjuvant imatinib for operable gastrointestinal stromal tumor: a randomized trial; JAMA. 2012 Mar 28;307(12):1265-72.

41. Joensuu H, Eriksson M, Sundby Hall K et al. Adjuvant Imatinib for High-Risk GI Stromal Tumor: Analysis of a Randomized Trial. J Clin Oncol. 2016 Jan 20;34(3):24450 .

42. Casali PG, Le Cesne A, Poveda Velasco A et al. Time to Definitive Failure to the First Tyrosine Kinase Inhibitor in Localized GI Stromal Tumors Treated With Imatinib As an Adjuvant: A European Organisation for Research and Treatment of Cancer Soft Tissue and Bone Sarcoma Group Intergroup Randomized Trial in Collaboration With the Australasian Gastro-Intestinal Trials Group, UNICANCER, French Sarcoma Group, Italian Sarcoma Group, and Spanish Group for Research on Sarcomas; J Clin Oncol. 2015 Dec 20;33(36):4276-83.

43. Gupta S, Amit K, Gupta A, Argawal T. GIST: Institutional Experience at SRMS-IMS, India; Gulf J Oncolog. 2016 Sep;1(22):64-6.

44. Suresh Babu MC, Chaudhuri T, Babu KG et al. Metastatic gastrointestinal stromal tumor: A regional cancer center experience of 44 cases.; South Asian J Cancer. 2017 JulSep;6(3):118-121

45. Zanwar S, Ostwal V, Sahu A et al. Rectal GIST-Outcomes and viewpoint from a tertiary cancer center; Indian J Gastroenterol. 2016 Nov;35(6):445-449

46. Pai VD, Demenezes JL, Patil PS, Saklani AP Multimodality therapy of rectal gastrointestinal stromal tumors in the era of imatinib-an Indian series; J Gastrointest Oncol. 2016 Apr;7(2):262-8

47. Sahu A, Godbole S, Jain P et al. Sunitinib in patients with imatinib-resistant gastrointestinal stromal tumor: A single center experience study; Indian J Cancer. 2015 JulSep;52(3):320-3

48. Yacob M, Inian S, Sudhakar CB Gastrointestinal Stromal Tumours: Review of 150 Cases from a Single Centre; Indian J Surg. 2015 Dec;77(Suppl 2):505-10.

49. Borgaonkar V, Deshpande S, Borgaonkar V, Rathod M Gastrointestinal Stromal Tumor-Single-Center Experience with Review of the Literature; Indian J Surg. 2015 Dec; 77(Suppl 2): 678-681. 